\title{
Investigation of hepatitis A outbreak in district of Manjung, Perak, Malaysia, October 2012
}

\author{
Faudzi Ahmad Yusoff, ${ }^{a}$ Rusdi Abdul Rahman, ${ }^{b}$ Ling He May, ${ }^{c}$ Suzana Binti Budart ${ }^{c}$ and Lokman Hakim Sulaiman ${ }^{d}$ \\ Correspondence to Faudzi Ahmad Yusoff (e-mail: faudzi@imr.gov.my).
}

Background: In September 2012, 10 cases suspected to be hepatitis A were notified to the Manjung District Health Department. An investigation was conducted to identify the possible mode of transmission, source of the outbreak and to recommend prevention and control measures.

Methods: A case was a person with acute illness with discrete onset of symptoms and jaundice or elevated serum aminotransferase levels in September 2012 in the Manjung District. We conducted a case-control study and environmental assessments of processing plants and food premises.

Results: There were 78 confirmed cases of hepatitis A; an attack rate of 3.1 per 10000 population. Multiple logistic regression showed that being male (odds ratio [OR]: 18.4 [5.13-65.9]; $P<0.001$ ) and drinking toddy at processing place A (Adjusted OR: 2.70 [1.17-6.25]; $P<0.05$ ) were associated with being a case. Environmental investigations of this and one other processing place found them to be unhygienic, and the $\mathrm{pH}$ of the toddy was at levels that encouraged growth of hepatitis A virus.

Conclusion: Toddy was possibly the primary source of this outbreak based on both epidemiological and environmental results. Both toddy preparation places and several food premises were closed as a result of this investigation.

$\mathrm{H}$ epatitis A virus (HAV) infection occurs globally and is more common where sanitation is poor. HAV is primarily transmitted by the faecal-oral route, person-to-person contact or ingestion of contaminated food and drink. ${ }^{1}$ One of the most common reported routes of foodborne-associated hepatitis $A$ is shellfish consumption. ${ }^{1,2}$ In India, cases of hepatitis A have been linked to the consumption of toddy, an alcoholic drink made from the sap of coconut and other palm trees.

Manjung is a district in the south-western part of the state of Perak, Malaysia. The most common ethnic groups are Malay (160 650), Chinese (76 500), Indians (12 750) and others (5100). ${ }^{3,4}$ The major sectors of economy in the Manjung District are agriculture and tourism. ${ }^{3}$ Coconut is one of the crops grown in Manjung with the sap used to produce toddy drinks. The flower clusters of the coconut are incised, fermented and drank as toddy. Toddy is usually served within a day, unless preserved in a chiller. The Manjung Health
District Department received notification from the district hospital of 10 cases of suspected hepatitis A on 19 September 2012. Cases presented with the typical signs and symptoms of hepatitis A, and serology samples were positive for HAV IgM. We conducted an investigation to identify the source, mode of transmission and to recommend control measures.

\section{METHODS}

\section{Epidemiological investigation}

We conducted a case-control study. Routine notifications from health-care providers were reviewed, and active case finding was conducted among high-risk groups such as food handlers, workers at food premises and household members of cases. A suspect case of hepatitis A was a person with an acute illness with discrete onset of symptoms and jaundice or elevated serum aminotransferase levels from September 2012 in Manjung District. A confirmed case was serologically

\footnotetext{
Unit of Epidemiology and Biostatistics, Medical Research Resource Centre, Institute for Medical Research, Ministry of Health, Kuala Lumpur, Malaysia. Melaka State Health Department (Public Health), Hang Tuah Jaya, Melaka, Malaysia.

Manjung Health District Department, Perak Darul Ridzuan, Malaysia.

Office of the Deputy Director General of Health (Public Health), Ministry of Health Malaysia, Putrajaya, Malaysia.

Submitted: 20 February 2015; Published: 27 May 2015

doi: 10.5365/wpsar.2015.6.1.012
} 
positive for HAV IgM antibodies. Controls were randomly selected from the same housing area as cases, were without signs and symptoms and returned negative HAV tests.

We conducted face-to-face interviews using a structured questionnaire that included questions on socio-demographics, food items eaten and activities related to possible ways of transmission. We also included questions pertaining to eating seafood and drinking toddy. Questions pertaining to specific events in September 2012, such as the Eid al-Fitr festival, were also included.

Univariable and multiple logistic regression analyses were performed using STATA 11 software. A backward multiple logistic regression model was applied and multicollinearity and interaction terms were checked. A Hosmer-Lemeshow test, classification table and area under the ROC curve were applied to check the model of fitness.

\section{Laboratory investigation}

Blood specimens were sent to the Public Health Laboratory in Sungai Buloh, Selangor and Kinta, Perak for serological tests for HAV (IgM).

\section{Food and environmental investigation}

Investigations were conducted at two toddy processing places and 341 food premises. A selection of food handlers were tested for hepatitis $A$ based on place of work and type of food they sold. Environmental samples such as ice cubes from the factory, toddy, seafood and well water were collected for laboratory test by polymerase chain reaction. The $\mathrm{pH}$ of toddy samples at various levels of manufacturing was also determined.

\section{RESULTS}

There were 78 cases of hepatitis $A$ with an attack rate of 3.1 per 10000 population. The majority of the cases were male (95\%) with an age range of 13 to 72 years (mean 31.4 years). There was a higher proportion of cases in the subdistricts of Ayer Tawar (47.4\%) and Sitiawan (37.2\%). Most cases occurred among Indians (5.1 per 1000 population), were aged 25-40 years, worked as labourers and were of low income (Table 1). The date of onset for the first notified case was
8 September 2012 (Figure 1). The epidemic curve shows a propagated shape, as the cases increased until 19 September 2012 with a second peak on 24 September 2012 . Then the cases gradually decreased to the lowest level after 25 September 2012, and only a few cases were reported since 11 October 2012.

\section{Analytical study}

Univariable analysis showed many significant variables $(P<0.05)$ including being male; eating outside the home; eating seafood; drinking alcohol, including toddy and beer; more frequent eating and drinking alcohol during the week of the Eid al-Fitr festival and several other variables regarding drinking toddy at different occasions (Table 1).

After multivariable analysis, only males (adjusted odds ratio [AOR]: 18.4 [5.13-65.0]) and those who drank toddy at processing place A (AOR: 2.7 [1.17-6.25]) were statistically significant.

\section{Environmental assessment}

Toddy is produced at processing places A and $B$, and it can be bought directly and consumed at the processing places or distributed to other food premises. Observation at the processing places showed both of them to be unhygienic. There were no toilets available; toddy was mixed with bare hands; a common bucket was used before bottling; and well water was used to wash at the premises, including the washing of utensils. The well water from processing place $B$ was positive for coliforms. All environmental specimens were negative for HAV. The $\mathrm{pH}$ level of toddy at harvesting was 3.37-3.63 and at of bottling was 3.07-3.27. Toddy specimens were unable to be tested for HAV.

A total of 341 food premises were inspected; 10 premises were closed under the Malaysian Food Act 281 and four under the Centers for Disease Control Act 1988. All 67 food handlers tested for HAV were negative, although $71.6 \%$ were reactive to total antibody. Samples taken from restaurants such as ice cubes, treated water and piped water supply were all negative for HAV.

\section{DISCUSSION}

Despite many local officials speculating that seafood and water were the sources of this outbreak, the results 
Table 1. Univariate analysis of case control study, Manjung, Perak, Malaysia, October 2012

\begin{tabular}{|c|c|c|c|c|}
\hline Characteristic & Case (\%) & Control (\%) & OR (95 Cl) & $P$-value \\
\hline \multicolumn{5}{|l|}{ Gender } \\
\hline Male & 75 (96.2) & $37(47.4)$ & $27.7(8.0-95.4)$ & $<0.001$ \\
\hline Female & $3(3.8)$ & $41(52.6)$ & Reference & \\
\hline \multicolumn{5}{|l|}{ Age group } \\
\hline$<20$ & $11(14.1)$ & $8(10.3)$ & Reference & \\
\hline $21-30$ & $28(35.9)$ & 27 (34.6) & $0.8(0.3-2.2)$ & 0.600 \\
\hline $31-40$ & 25 (32.1) & $17(21.8)$ & $1.1(0.4-3.2)$ & 0.905 \\
\hline $41-50$ & 10 (12.8) & $8(10.3)$ & $0.9(0.3-3.3)$ & 0.886 \\
\hline $51-60$ & $3(3.8)$ & $12(15.4)$ & $0.2(0.0-0.9)$ & 0.032 \\
\hline 60 and above & $1(1.3)$ & $6(7.7)$ & $0.1(0.0-1.2)$ & 0.012 \\
\hline \multicolumn{5}{|l|}{ Ethnic group } \\
\hline Indian & 65 (83.3) & $63(80.8)$ & $1.0(0.1-16.9)$ & 0.983 \\
\hline Chinese & $12(15.4)$ & $13(16.7)$ & $0.9(0.1-16.5)$ & 0.957 \\
\hline Malay & $0(0)$ & $1(1.3)$ & Reference & \\
\hline Others & $1(1.3)$ & $1(1.3)$ & - & \\
\hline \multicolumn{5}{|l|}{ Occupation } \\
\hline Student & $5(6.4)$ & $6(7.7)$ & Reference & \\
\hline Housewife/not working & $6(7.7)$ & $28(35.9)$ & $3.9(0.9-17.1)$ & 0.720 \\
\hline Driver/student & $18(23.1)$ & $5(6.4)$ & $0.2(0.1-1.1)$ & 0.640 \\
\hline Government & $5(6.4)$ & $5(6.4)$ & $0.9(0.2-4.6)$ & 0.835 \\
\hline Self-employed & $8(10.3)$ & $4(5.1)$ & $0.4(0.1-2.3)$ & 0.309 \\
\hline Labourer & $30(38.5)$ & $26(33.3)$ & $0.7(0.2-2.6)$ & 0.623 \\
\hline Business & $6(7.7)$ & $4(5.1)$ & $0.6(0.1-3.1)$ & 0.507 \\
\hline \multicolumn{5}{|l|}{ Food and drink exposures } \\
\hline Eating out during Eid al-Fitr & $72(57.6)$ & $53(68.0)$ & $5.7(2.2-14.8)$ & 0.000 \\
\hline More than once a week & $63(80.8)$ & 27 (34.6) & $1.8(1.4-2.3)$ & 0.000 \\
\hline \multicolumn{5}{|l|}{ Eating food outside } \\
\hline Seafood & $32(41.0)$ & $19(24.4)$ & $2.2(1.1-4.3)$ & 0.028 \\
\hline Fish & 1.4 & 1 & 2.1 & 0.080 \\
\hline \multicolumn{5}{|l|}{ Drinking alcohol } \\
\hline Any alcoholic drink & $73(93.6)$ & $33(42.3)$ & $19.9(7.2-54.7)$ & 0.000 \\
\hline Beer & $52(66.7)$ & $23(29.5)$ & $4.8(2.4-9.4)$ & 0.000 \\
\hline Toddy & $56(71.8)$ & $21(26.9)$ & $6.9(3.4-14.0)$ & 0.000 \\
\hline More than once during Eid al-Fitr & $72(57.6)$ & $53(68.0)$ & $5.7(2.2-14.8)$ & 0.000 \\
\hline More frequent during Eid al-Fitr & $63(80.8)$ & 27 (34.6) & $1.8(1.4-2.3)$ & 0.000 \\
\hline At a processing place & $56(71.8)$ & $23(29.5)$ & $6.1(3.0-12.2)$ & 0.000 \\
\hline Processing place $\mathrm{A}$ & $12(15.4)$ & $1(1.3)$ & $14.0(1.8-110.5)$ & 0.012 \\
\hline Processing place $\mathrm{B}$ & $40(51.3)$ & $11(14.1)$ & $6.4(3.0-13.9)$ & 0.000 \\
\hline At a restaurant & $32(41.0)$ & $12(15.4)$ & $3.8(1.8-8.2)$ & 0.001 \\
\hline Drink from bottles & $20(25.6)$ & $8(10.3)$ & $3.0(1.2-7.4)$ & 0.015 \\
\hline Drink from stainless steel cup & $26(33.3)$ & $7(9.0)$ & $5.1(2.1-12.6)$ & 0.000 \\
\hline
\end{tabular}

$\mathrm{Cl}$, confidence interval; OR, odds ratio. 
Figure 1. Epidemic curve of the hepatitis A outbreak in Manjung, Malaysia, 8 September to 19 October 2012

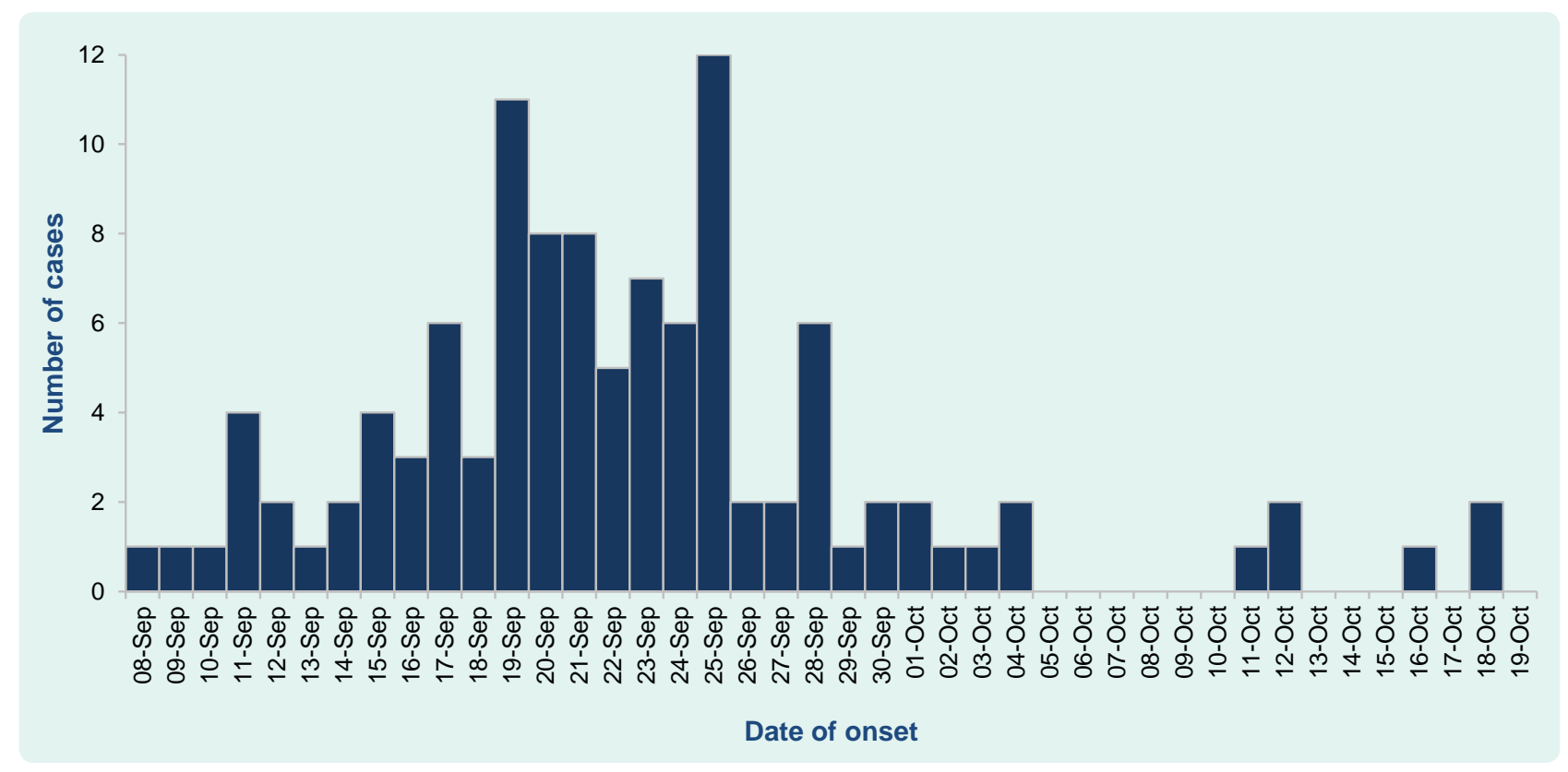

show that men who drank toddy were more likely to be hepatitis A cases. Even after controlling for all other foods items, seafood was not associated with being a case.

Toddy was the potential source of this outbreak with the time of exposure corresponding to when Malaysians celebrated the Eid al-Fitr festival. Although the Eid alFitr festival is a celebration for Muslim communities, almost all Malaysian communities celebrate the festival, too. Low standards of sanitation promote transmission of the HAV infection, ${ }^{5}$ and the environmental investigation found unhygienic conditions at both processing places, although the epidemiological investigation found that drinking toddy from processing place $A$ was associated with illness. HAV contamination of toddy can occur at any point of processing, ${ }^{6}$ and there was potential contamination observed during preparation, mixing, serving or using utensils washed in contaminated well water. The $\mathrm{pH}$ of the toddy tested ranged from 3.0 to 3.8 in which HAV can survive and multiply. Toddy is easy to access and cheaper than other alcoholic drinks, and it contains only $4-5 \%$ alcohol. ${ }^{7}$ Additionally, most cases occurred among Indians which may be related to their habit of drinking toddy. Attack rates among Chinese and Malays were very low, even though the majority of these two groups lived in the same outbreak areas. It should also be noted that all ethnic Malays are Muslim and therefore are prohibited to drink alcohol.

In this outbreak, we expect cases will continue to appear, which had been experienced elsewhere; outbreaks are often prolonged and difficult to control. ${ }^{5}$ Usually outbreaks may persist for six to 18 months until the pool of susceptible people is exhausted. ${ }^{8}$

There are some limitations in our investigation. Recall bias on food intake is one limitation, but this was reduced by asking questions pertaining to the Eid al-Fitr festival. We were also unable to test the presence of HAV in the toddy due to the unavailability of laboratory testing during the outbreak.

Despite these limitations, the investigation suggests that toddy was the source of this hepatitis A outbreak. As a result of this investigation, the toddy preparation places were closed. Cases were followed up weekly as they had the potential to be the source of secondary infection. We also recommended improved sanitary facilities and appropriate water quality for the field workers. 


\section{Conflicts of interest}

None declared.

\section{Funding}

The investigation was undertaken within the Ministry of Health activities.

\section{Acknowledgements}

We wish to acknowledge the Director General of Health Malaysia for his permission to publish this paper. We would like to thank the Director of the Perak State Health Department for his support of this study. We wish to extend our thanks to Dr Yeoh So Fan and Dr Haslinda Ismail and all staff of the Manjung District Health Department for helping us in this study, especially helping us with data entry, in addition to their role in preventing and controlling the disease. We also thank all staff of the Perak State Health Department for their contributions to this study.

\section{References:}

1. Yong HT, Son R. Review article: Hepatitis A virus - a general overview. International Food Research Journal, 2009, 16: 455467.

2. Cliver DO. Scientific status summary: virus transmission via food. Food Technology, 1997, 51:71-78 (http://www.ift.org/ / media/Knowledge\%20Center/Science\%20Reports/Scientific\%20 Status\%20Summaries/virustransmissionviafood_0497.pdf, accessed 4 May 2015).

3. Report MHDA. Perak Darul Ridzuan, Health State Department, 2011.

4. Basic population characteristic report. Putrajaya, Department of Statistics Malaysia, 2010.

5. Sowmyanaranan TV et al. Investigation of a hepatitis A outbreak in children in an urban slum in Vellore, Tamil Nadu, using geographic information systems. Indian Journal of Medical Research, 2008, 28:32-37.

6. Leong PC. The nutritive value of coconut toddy. The British Journal of Nutrition, 1953, 7:253-259. doi:10.1079/BJN19530030 pmid:13081939

7. Sarin SK, Kumar M. Viral hepatitis A. In: Monga SPS, editor. Molecular Pathology of Liver Diseases. Springer, 2011, 5:527552.

8. Health $T$ et al. A community-wide hepatitis $A$ outbreak in the Shoalhaven region, New South Wales. CDI, 1997, 21:9. 